\title{
A Rosa-CRUZ: os PRIMÓRDIOS DE UMA FRATERNIDADE ESOTÉRICA
}

\author{
The Rose Cross: the beginnings of a fraternity esoteric
}

\begin{abstract}
RESUMO O estudo da temática dos símbolos e das tradições filosófico-iniciáticas trouxe à luz este artigo. Baseando-nos na escassez de estudos na área, principalmente pela pouca quantidade de artigos científicos que tratem de tal temática, é que surgiu o interesse por pesquisar e dialogar com a história de uma das mais antigas e difundidas sociedades esotéricas existentes no mundo. Um enfoque histórico e fenomenológico foi importante para avaliar o atual estado da arte, cujo tema é bastante complexo, pois a ficção se mistura com o real e histórico. Por isso, o amparo em estudos de autores consagrados, como Eliade e Campbell, forneceu uma base científica necessária para a execução da pesquisa. $\mathrm{O}$ artigo trata, em linhas gerais, sobre o contexto histórico em que ocorreu o surgimento da Ordem Rosa-Cruz, bem como um pouco de sua mitologia.
\end{abstract}

Palavras-Chave: Religiões. Esoterismo. Rosa-Cruz. Símbolos.

\begin{abstract}
The theme of the study of symbols, philosophical and initiatory traditions inspired this article. Since there are not many studies in this area, neither scientific articles about this subject, a research about the history of one of the oldest and most widespread esoteric societies around the world seemed to be worthwhile. A historical and phenomenological view was important to assess the current state of the art knowing that the subject is also quite complex because it mixes fiction with reality and history. Therefore, the support from expert authors, such as Eliade and Campbel, provided a scientific basis for the execution of the research. What's more the article is about the historical background in which the emergence of the Rosicrucian Order occurred and some of its mythology as well.
\end{abstract}

KEY-WORDS: RELIGIONS. ESOTERICISM. ROSICRUCIAN. SYMBOLS.

\section{INTRODUÇÃO}

$\mathrm{O}$ presente artigo é fruto de pesquisas realizadas no âmbito das religiões, com um enfoque fenomenológico em tradições ditas ocultas e esotéricas. Utilizamos o termo fenomenológico, pois é com esse método que o trabalho se constitui. Além deste destaque fenomenológico, a pesquisa consiste também em um levantamento bibliográfico de autores como Elia-

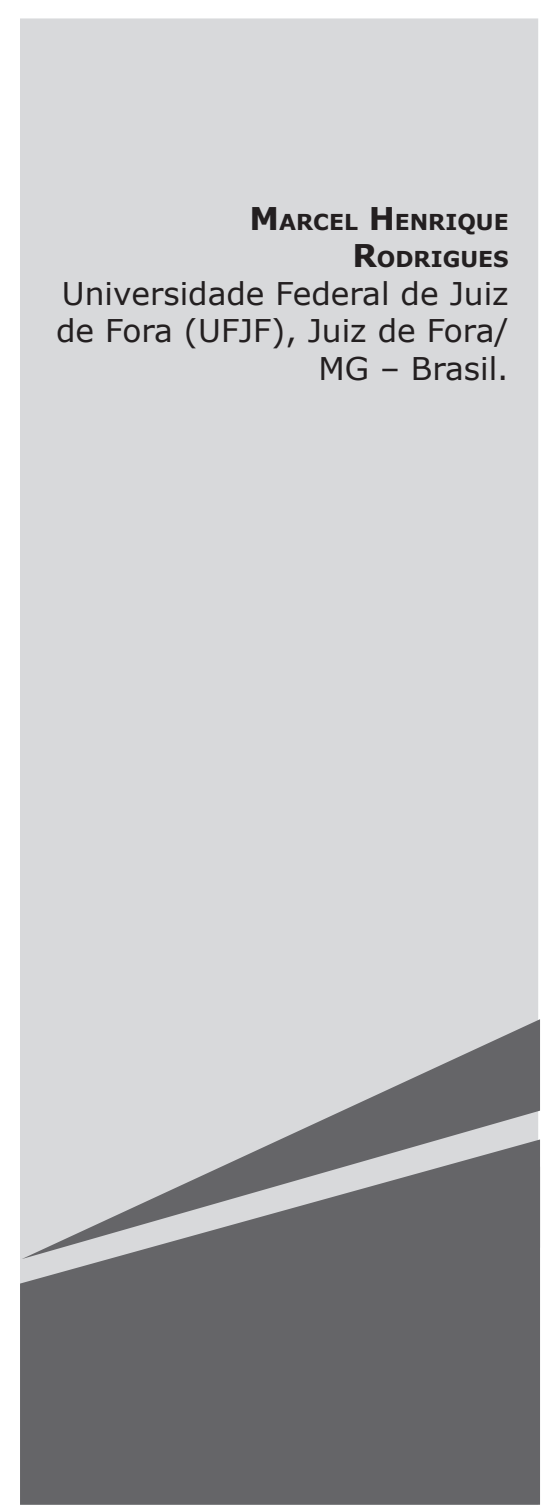


de e Campbell, tomando o cuidado para que não haja o enfoque em obras cujo teor seja tendencioso e com afirmações a respeito da existência do sobrenatural.

Em suma, a ideia geral do trabalho é mostrar como o cenário histórico-cultural europeu fora decisivo para a organização de sociedades esotéricas, como a Rosa-Cruz. E também demonstrar como essas sociedades, ditas "secretas", influenciaram vários ramos sociais, sobretudo a formulação da Ciência Moderna.

Concluiremos apontando como os símbolos e antigas tradições sobrevivem ao pesado tempo da história, enfocando a dimensão simbólica do ser humano, que se abre para novas perspectivas filosóficas e religiosas, para a exploração e explicação do enigma da vida.

\section{PANO DE FUNDO PARA O ESTUdO DA TEMÁTICA}

Tem-se discutido sobre a existência de sociedades e irmandades secretas que velam para si a posse de segredos e conhecimentos místicos advindos das mais diversas religiões e filosofias mundiais. No entanto, a falta ou a má qualidade de material científico acerca da temática torna-se uma dificuldade para o pesquisador que deseja vasculhar esse fascinante universo de sociedades fraternais, como no caso da Rosa-Cruz. Podemos fazer um adendo e verificar que existem bons livros a respeito da temática, porém, são poucos os artigos que debatem o assunto, o que pode ser reflexo de preconceitos aos estudos concernentes ao misticismo e ao esoterismo. É conhecida a problemática envolvendo pesquisas sobre religiões no meio acadêmico. Muitas vezes, o assunto é tratado com descaso, os acadêmicos esquecem-se de que a religião, acima de tudo, é um fator social, portanto, um objeto claro de estudo, como indica Greschat (2005).

Os cursos de Teologia e Ciência da Religião têm ganhado campo por todo o Brasil, e cada vez mais instituições de Ensino Superior abrem cursos em áreas em que o fenômeno da religião é amplamente estudado. Assim, percebemos um "esquecimento" das antigas tradições esotéricas que permearam e per- meiam diversas religiões e escolas filosóficas, uma vez que muitos dos conhecimentos esotéricos ainda estejam, de certa forma, reservados hoje aos iniciados de tais fraternidades, como, por exemplo, a Maçonaria e a RosaCruz. Esse "esquecimento" ou não aprofundamento em pesquisas pode ser reflexo desse comportamento.

É com esse pano de fundo que propomos estudar os aspectos de fraternidades que relegam para si o conhecimento de diversas práticas esotéricas das mais diversas culturas. A escolha da fraternidade Rosa-Cruz se deu por sua ampla disseminação pelo mundo.

\section{ANTECEDENTES PARA O SURGIMENTO DA ORDEM}

É muito comum encontrarmos na internet e em livros as mais diversas teorias sobre o surgimento de Ordens místicas. A principal delas consiste em postular que o surgimento das Ordens esotéricas, como a Rosa-Cruz, por exemplo, tiveram seus inícios no Egito Antigo, Grécia, entre outros lugares da Antiguidade. Essa teoria é corroborada pelo fato de que foram nessas antigas civilizações, como indica Lurker (2003), que muitas das doutrinas místicas e esotéricas ${ }^{1}$ tiveram suas origens, como a Astrologia, por exemplo. Em praticamente todo o decorrer histórico das religiões é possível encontrar grupos que, de certa forma, se distanciavam da religião estabelecida e criavam grupos iniciáticos que se propunham a estudar e conhecer os mistérios do universo. Essas "ramificações religiosas" ficaram conhecidas como "religiões de mistérios", como bem estudou Eliade (2010).

Manthéia (1995) busca explicar a dificuldade em estabelecer quando ocorreu o surgimento do chamado "culto aos mistérios". Tal culto está relacionado com os ensinamentos sobre os enigmas e os "poderes" da própria natureza

\footnotetext{
Os termos místicos e esotéricos não são fáceis de conceituar. No imaginário popular esses termos ficaram reservados às práticas e crenças na Astrologia, no Horóscopo etc. No entanto, se bem averiguado, todas as religiões possuem sua parte mística e esotérica, não se restringindo aos ensinamentos da Astrologia, Horóscopos, Numerologia, entre outros.
} 
humana, universal e divina que o homem pode conhecer, desenvolver e praticar. Isso demonstra certa singularidade, embora esse culto seja oriundo da própria cultura religiosa. Essas práticas, ainda que muito difundidas na religiosidade pagã, passaram a ser bem mais exaltadas e praticadas em clubes filosóficos, esotéricos e herméticos. A autora elenca algumas dessas "escolas ou cultos aos mistérios":

A orientação pode também ser buscada com maior sistematização nas Ciências Ocultas e as mais próximas do lado ocidental são em número de três, conforme observa Papus:

A Cabala ou ciência tradicional, que poderia chamar-se matemática do pensamento humano. É a álgebra da Fé, resolvendo todos os problemas da alma como se fossem equações, isolando as incógnitas. Dá às idéias a nitidez e a rigorosa exatidão dos números; seus resultados são, para o espírito, a infalibilidade (relativa, entretanto, à esfera dos conhecimentos humanos), e a paz profunda para o coração.

A Magia ou ciência dos magos, que teve por representantes na Antiguidade os discípulos e talvez os mestres de Zoroastro, é o conhecimento das leis secretas e particulares da Natureza, que produzem as forças ocultas, ou ímãs, quer naturais ou artificiais, que podem existir mesmo fora do mundo metálico. Em uma palavra, para empregar uma expressão moderna, é a ciência do magnetismo universal.

O Hermetismo é uma ciência da natureza oculta nos hieróglifos e símbolos do mundo antigo. É a procura do princípio da vida com o sonho (para aqueles que ainda não chegaram), da realização da grande obra, a reprodução pelo homem, do jogo natural e divino, que cria e regenera os seres (MANTHÉIA, 1995, p. 30).
A autora indica os principais meios pelos quais os mistérios da natureza eram explorados. Seria um erro afirmar, por exemplo, que o cristianismo não tenha se deslumbrado frente aos mistérios da existência humana. Palavras como esoterismo, ciências ocultas e hermetismo estavam totalmente fora da doutrina cristã. Por isso, mesmo após a ascensão do cristianismo como religião dominadora do Ocidente, muitas escolas de cunho esotérico mantiveram seus cultos e ritos, apesar de toda a condenação e perseguição por parte da religião cristã.

Não é da alçada deste artigo realizar um julgamento histórico por parte da tradição cristã católica frente aos grupos que não se delimitavam aos seus dogmas. Ao contrário, o intuito é demonstrar como a formação de sociedades secretas, além de um produto da própria cultura religiosa humana, também passou a ser uma necessidade vital para que certos "segredos" pudessem ser estudados, praticados e transmitidos de forma segura.

Como menciona Kinney (2006), a própria crença de que o homem seja parte da divindade e que com práticas e conhecimentos específicos o mesmo possa alcançar certos poderes divinos, fez que diversos grupos com essa concepção se tornassem herméticos para se livrarem das duras imposições dogmáticas do cristianismo, que apontava como uma forte heresia para o credo cristão que sempre distinguiu a criação do Criador.

\section{A COMPLEXA ORIGEM DE UMA ORDEM ESOTÉRICA: A ROSA-CRUZ}

Explorar a natureza histórica de uma sociedade que permaneceu secreta, ou para não dizer na clandestinidade por centenas de anos, é uma tarefa difícil para o cientista que estuda o fenômeno religioso. Essa dificuldade advém das inúmeras fontes bibliográficas que postulam sobre as histórias das Ordens esotéricas baseando seus primórdios, por exemplo, no Egito e na Grécia Antiga. Ora, a afirmação não pode ser levada em consideração por um estudioso que preze por comprovações histó- 
ricas que possam afirmar, com validade científica, tal origem.

Milhomens (1997) afirma que o esotérico, o místico, ou seja, aquilo que vai além do que nos é apresentado, é encontrado em todas as tradições religiosas. $\mathrm{O}$ autor faz uma distinção entre misticismo e religião:

Não! Absolutamente, o Misticismo não é uma religião! Nunca se esqueça de que toda e qualquer religião deriva, direta ou indiretamente, do Misticismo.

Misticismo é um tipo de Conhecimento - conforme já foi dito anteriormente - e Religião é um tipo de crença baseada na Revelação, nos Rituais e nos Dogmas. O religioso não experimenta, não aceita a menor dúvida sobre o cerne de sua crença ou doutrina, pois aquilo em que acredita é a Verdade Suprema e Absoluta revelada por uma "Entidade Superior" - um deus, um espírito, um anjo, etc, - para o "Eleito", o fundador daquela religião.

Já o Misticismo parte de princípios obtidos através da experimentação pessoal e individual - sem a mínima conotação de Revelação - e também da comprovação e repetitividade de tudo aquilo que é ensinado para os seus estudantes. $O$ Misticismo admite inovações e retificações, enfim, aceita acréscimos de novos conhecimentos ou, então, até mesmo a supressão de algumas coisas que antes eram entendidas de uma certa maneira e que, com o decorrer dos tempos e das experimentações, constatou-se serem exatamente daquela maneira como era ensinada anteriormente e, por esse motivo, deverão ser abandonadas ou modificadas (MILHOMENS, 1997, p. 150-151).

A ponderação da diferenciação e do encontro entre esoterismo e religião é bastante pertinente ao se tratar de um tema tão complexo como a história de uma fraternidade esotérica, como no caso da Rosa-Cruz. Muitos autores são propensos a dissertar sobre as origens da Rosa-Cruz no Egito Antigo, passando por outras civilizações como Roma e Grécia, vinculando o esoterismo desses povos com o esoterismo da mencionada fraternidade. Embora exista certa similaridade entre conceitos rosacrucianos e do mundo antigo, principalmente em seus símbolos, é impossível fazer uma afirmação científica acerca dessa duvidosa origem.

Como menciona Churton (2009), a existência de confrarias secretas e iniciáticas advém da própria cultura religiosa da humanidade. Talvez seja com essa mesma cultura religiosa da construção de clubes filosóficos, seleta apenas aos iniciados, que podemos, com certo risco, fazer uma analogia entre a atual Rosa-Cruz e as antigas fraternidades do Egito, por exemplo. Um estudo mais aprofundado de um suposto "vínculo" das antigas tradições iniciáticas com as tradições esotéricas da atualidade pode ser encontrado em nosso estudo anterior sobre "Maçonaria e Simbologia” (Rodrigues, 2014). No entanto, é seguro afirmar que tal analogia não leva a postular - historicamente dizendo - que a Rosa-Cruz, por exemplo, esteja vinculada às milenares práticas do esoterismo egípcio, por exemplo, como se tal esoterismo de tão tarda antiguidade não tivesse, de modo algum, se perdido.

É possível viver a espiritualidade, e os enigmas e os símbolos esotéricos como faziam os egípcios, no entanto, somente por analogia. Em termos científicos, não existem provas cabais que ligam a contemporaneidade das atuais sociedades esotéricas, com as sociedades do mundo antigo.

\section{ENTRE O MÍTICO E O HISTÓRICO: OS PRIMÓRDIOS DA ROSA-CRUZ}

No item anterior, apontamos a tradição existente entre as Ordens esotéricas atuais, responsáveis por postular sobre suas origens em cultos e filosofias do mundo Antigo. A história da Ordem Rosa-Cruz também tangencia 
por esses meios. Suas origens nos primórdios do século XVII estão marcadas pelo real e o mítico. Como estuda Churton (2009), a mítica história do monge Christian Rosenkreuz, possível fundador da Rosa-Cruz, permeava a mente daqueles que traziam a Ordem para a exposição pública. ${ }^{2}$ Sua mítica história merece ser rapidamente considerada.

Os manifestos Rosa-Cruzes surgem no início do século XVII, atribuídos a Johannes Valentinus Andreae (1586-1654), um teólogo alemão que, possivelmente, recebeu ajuda de outras importantes figuras, como Tobias Hess (1558-1614). Os manifestos são uma mescla de misticismo gnóstico com referências alquímicas que incitam uma nova revolução espiritual da humanidade. McIntosh (2001) declara que com a publicação dos manifestos, a Ordem Rosa-Cruz é finalmente "inaugurada", sendo que nesses escritos encontramos a mítica figura do fundador da Ordem, Christian Rosenkreuz.

Segundo o mito, Rosenkreuz teria sido um monge alemão que, desde muito jovem, empreendeu uma viagem pelo mundo em busca de sabedoria e conhecimento. De acordo com os manifestos, o mítico Christian teria viajado por grande parte do Oriente, estabelecendo contato e adquirindo conhecimento místico das mais diversas filosofias orientais. Conta-se que o monge teria descoberto e aprendido muito sobre ocultismo, ao passo que conseguiu prolongar sua vida até os 106 anos de idade. Quando morreu, seu corpo fora selado em uma tumba, que permaneceu escondida por 120 anos. Como menciona McIntosh (2001), após a descoberta de seu corpo a existência da Ordem rosacruciana finalmente pôde ganhar publicidade.

Embora nunca se soubesse da real existência desse mítico fundador, muito menos sobre o paradeiro de sua tumba, tal jornada

\footnotetext{
Toda ordem esotérica prega para si, como já mencionado, uma mítica história que remonta suas origens em tempos longínquos. Não descartamos que muitas sociedades secretas tiveram seu período "encoberto" antes de virem a público. No entanto, somente discorreremos sobre as origens da RosaCruz no início do século XVII.
}

arquetípica fora essencial para o desabrochar do esoterismo ocidental, que culminou com o surgimento da Ordem Rosa-Cruz, bem como, o aparecimento de inúmeras fraternidades esotéricas. A figura de Rosenkreuz está para além do possível fundador da mencionada fraternidade. Ela é, acima de tudo, um símbolo. O símbolo de um herói que cumpre sua jornada. Essa temática foi bastante discutida por Campbell (2009), o mais eminente mitólogo do século XX.

Para o estudioso, as figuras das grandes religiões, por exemplo, representam heróis que cumprem sua jornada terrestre, deixando um legado à humanidade. Não é raro, nesse mito arquetípico do herói, que figuras como de Buda e Jesus Cristo, por exemplo, após longa jornada terrestre difundindo mensagens de paz e esperança, inaugurem uma nova era para a humanidade. Geralmente, suas próprias figuras, no fim de suas jornadas, acabam por morrerem e renascerem, completando o símbolo máximo do arquétipo do herói.

Existe uma certa seqüência de ações heróicas, típica, que pode ser detectada em histórias provenientes de todas as partes do mundo, de vários períodos da história. $\mathrm{Na}$ essência, pode-se até afirmar que não existe senão um herói mítico, arquetípico, cuja vida se multiplicou em réplicas, em muitas terras, por muitos, muitos povos. Um herói lendário é normalmente o fundador de algo, o fundador de uma nova era, de uma nova religião, uma nova cidade, uma nova modalidade de vida. Para fundar algo novo, ele deve abandonar o velho e partir em busca da idéia-semente, a idéia germinal que tenha a potencialidade de fazer aflorar aquele algo novo. Os fundadores de todas as religiões se consagraram a buscas como essa. O Buda recolheu-se em isolamento, depois sentou-se sob a árvore bo, a árvore do conhecimento 
imortal, onde recebeu a iluminação que iluminou toda a Ásia por vinte e cinco séculos.

Depois de ser batizado por João Batista, Jesus se isolou no deserto por quarenta dias e dali voltou com sua mensagem. Moisés foi ao topo da montanha e retornou com as tábuas da lei. E você tem aquele que funda uma cidade - quase todas as velhas cidades gregas foram fundadas por heróis que partiram em expedição e viveram aventuras surpreendentes, a partir das quais cada um fundou uma cidade (CAMPBELL, 2009, p. 145).

A ponderação de Campbell (2009) pode ser articulada ao mito do mítico fundador da Rosa-Cruz, como uma arquetípica jornada do herói. No caso de Rosenkreuz, ele teria aberto uma nova era para o esoterismo no mundo ocidental. Dissertar sobre o universo rosacruciano sem mencionar seu mítico fundador seria retirar grande parte do misticismo que envolve a Ordem. No entanto, em termos históricos, associamos o surgimento da fraternidade à divulgação de seu primeiro manifesto no século XVII - como já mencionado -, embora a possibilidade de sua existência, anterior a essa data, não esteja excluída pelos historiadores, como alega Churton (2008).

Entre as primeiras apresentações da Rosa-Cruz a público, ocorreu por meio de dois manifestos, o primeiro em 1614 e outro, um ano mais tarde, em 1615. Há um terceiro manifesto conhecido como "As Bodas Alquímicas de Christian Rosenkreuz", 3 de 1616.

A Fama Fraternitatis, de 1614, o tratado que traz o mítico Rosenkreuz, glorifica a figu-

3 As Bodas, por sua vez, deixam o tom de um direto manifesto que encontramos nos dois escritos anteriores, para assumir uma linguagem extremamente simbólica. Esse conto, muito mais que um tratado, relata através de símbolos e jogos de linguagem o casamento entre um homem e uma mulher. Opostos, que se unirão. Uma das interpretações para o texto, entre várias, consiste em apontar no "sagrado" casamento interior do indivíduo entre alma e espírito. ra do homem sendo ele reflexo de uma realidade muito superior, a realidade divina e macrocósmica. O texto segue mencionando que os ensinamentos de Rosenkreuz foram passados para um pequeno grupo de "iniciados" e que cabe agora a Rosa-Cruz dar continuidade na permanência desses conhecimentos sagrados.

Já a Confessio Fraternitatis, de 1615, ao contrário do tom otimista do tratado anterior, assume um tom bastante "protestante" ao fazer uma crítica ao mundo religioso oriental e ocidental. O tom da Confessio é bastante apocalíptico. Apregoa uma radical mudança no mundo ou, ao menos, proclama a necessidade dela. Em termos gerais a Confessio desenvolve a ideia de que apenas a digna Ordem Rosa-Cruz pode oferecer uma nova e verdadeira "revelação" que renovará o mundo. ${ }^{4}$

Outro adendo necessário para argumentar sobre a parte histórica da Ordem rosacruciana está no próprio momento da publicação do primeiro manifesto, ou seja, o início da Era Moderna. Tal período, como admite Kinney (2006), é considerado o momento do "boom" para a exploração, por parte de todos os níveis da sociedade, de antigos símbolos, conceitos e ritos da Antiguidade, pós ou pré-cristãs. Devemos mencionar a importante figura de Henrique Cornélio Agrippa de Nettesheim (1486-1535) que, muito influenciado pelos estudos herméticos do período medieval, iniciou uma grande empreitada, por volta de 1510, para escrever uma compilação sobre filosofia oculta.

A mencionada compilação permanece até os dias de hoje, está editada em três livros, fonte de grande conhecimento sobre o esotérico do mundo ocidental. A figura de Agrippa, apesar de um expoente, é apenas

4 Em paralelo com a temática da Confessio podemos fazer um cotejo com as ideias do filósofo italiano Giordano Bruno (1548-1600), que esteve envolvido com a filosofia hermética. Bruno depositava sua fé em uma renovação religiosa do Ocidente, por meio dos conhecimentos herméticos, articulou a ideia que a antiga religião egípcia, com seus enigmáticos hieróglifos, pudesse ser a chave para essa revolução religiosa. 
um dos muitos personagens que se destacaram na época na exploração do mundo esotérico. O gosto pelo esotérico, mágico, eclodiu em toda a Europa no período da Renascença e, de certa forma, formou todo o terreno para o surgimento de novas e antigas sociedades secretas, como a estudada Ordem Rosa-Cruz.

Outro dado histórico com grande relevância para o período, como afirma Kinney (2006), foi a descoberta dos manuscritos do Corpus Hermeticum em Bizâncio, na data de 1460, o que impulsionou consideravelmente os estudos esotérico-ocultistas, permitindo-lhes sair da escuridão da Idade Média e ganhar mais claridade no período do Renascimento, ou seja, da Era Moderna.

Embora esta pesquisa pudesse estar focada na Alemanha do século XVII, onde nasceu a Rosa-Cruz com o círculo Tübingen, achamos por bem dissertar sobre os primórdios que forneceram subsídios e terreno fértil para o surgimento, ou melhor, para o reavivamento de antigos símbolos e rituais místico-religiosos. O terreno, de fato, era muito fértil. O início do século XVII estava marcado por grande expectativa, tanto no campo religioso quanto no social. Como aponta Churton (2009), a perda do poder da Igreja Católica, devido à Reforma Protestante, às guerras políticas, aos novos avanços na Ciência, sobretudo em Kepler, Bacon e Galileu, geraram certo "entusiasmo" na sociedade europeia que acreditava que estava para acontecer uma forte mudança, tanto de cunho social-político quanto no campo religioso. Alguns acreditavam na iminente vinda do Messias e no fim dos tempos. Por sua vez, as guerras religiosas, sobretudo a Guerra dos Trinta Anos, abriam caminho para que as propostas esotéricas ganhassem terreno. Podemos afirmar que a grande instabilidade religiosa da época tornou-se bastante propícia para um grande salto, para o surgimento e o interesse por assuntos em torno do ocultismo, esoterismo, onde pulularam os surgimentos de sociedades iniciáticas.

De fato, uma forte mudança na sociedade ocorreu com os acontecimentos históricos que bem conhecemos e que estão relaciona- dos com o início da Era Moderna, como as novas descobertas científicas e a grande reforma religiosa. No entanto, o objetivo desta investigação é apontar que, para além desses fatos, a mudança também compreendeu um reavivamento do simbólico místico-religioso, bem como o enaltecimento de antigos conceitos filosóficos, como o Neoplatonismo e o Gnosticismo, por exemplo, sendo que esses acontecimentos se refletiram, em certa medida, no próprio movimento Rosa-Cruz.

O início da Era Moderna abarcou novas estruturas políticas e religiosas que modificaram grande parte da estrutura social europeia. Um desses pontos permeia a revolução científica que, apesar dos entraves impostos pela religião cristã, sobretudo pelo Catolicismo romano, não teve sua exploração impedida. Lomas (2007), que estudou profundamente o mencionado período, articula a ideia de que o "boom" do reavivamento do misticismo e do esoterismo ocidental foi fundamental para o surgimento da Ciência Moderna. A afirmação pode ser ancorada à ideia de que antigos alquimistas, precursores da Química moderna, amparados em uma abordagem demasiadamente esotérica, exploravam elementos químicos, fornecendo margens para descobertas de medicamentos e produtos químicos.

Churton (2008) admite que o cansaço dos antigos dogmas religiosos e a "ânsia" pela exploração do mundo sensível, empírico, influenciou profundamente muitos intelectuais que se interessavam pelos novos movimentos esotéricos que eclodiam por toda a Europa, tendo em vista principalmente o movimento Rosa-Cruz. Esse apêndice na história da estudada fraternidade traz uma reflexão de como a Ciência ainda permanecia profundamente interligada com a religiosidade, mesmo dentro dos círculos mais esotéricos e herméticos.

A História da Ciência nos legou muitos nomes, como de Agrippa, Paracelso (14931541) e John Dee (1527-1608) que entre os séculos XVI e XVII transitaram entre os experimentos científicos e o esoterismo corrente. Dee, por exemplo, acreditava na perfeita 
união entre Ciência e religião, uma complementando a outra. Esses homens estavam crentes que, ao explorar a natureza, através de seus experimentos, poderiam entrar em contato, finalmente, com um "poder superior”, divino, a causa do mundo.

É nesse sentido que esses homens, assim como muitos outros, estavam envolvidos com o grande impulso esotérico daquele momento, e envolvidos com a "causa" Rosa-Cruz. Churton (2009) conclui que entre a simbologia esotérica, passando pelos estudos da Cabala, e o reavivamento de correntes gnósticas, os rosa-cruzes também muito se interessaram pelos estudos científicos em torno da natureza. $\mathrm{O}$ autor aponta que esse interesse possa ser uma alusão aos estudos e ensinamentos da própria fraternidade que imbuíra o homem de certa autonomia espiritual, na busca pela sua própria iluminação. Em vista disso, tal alusão poderia ser um caminho ou um convite para o estudo do meio empírico que circunda o homem. Eis como o estudioso fundamenta esta tese:

As idéias rosa-cruzes eram simplesmente idéias científicas pré-modernas.

De fato, o conceito-chave "rosa-cruz" mais natural ao movimento foi isolado há uns 350 anos pelo gênio tcheco Comênio (1592-1670), quando expressou um entusiasmo pela "Pansofia" em sua obra prima O labirinto do mundo e o paraíso do coração, escrito, significativamente, em 1623. O impulso para a criação de uma Pansofia era comum no século XVII: a integração de todo o conhecimento em um único sistema científico, inclusive causas espirituais e correspondências celestes - uma Harmonia global, celestial e supracelestial.

Heinrich Nollius (expulso de Giessen, em 1623, por sua postura pró-rosa-cruz) definiu Pansofia como Teosofia mais alquimia e astrono- mia. Porém, nas mãos de homens inspirados por sir Francis Bacon e nos textos associados aos fratres R.C., Pansofia também podia significar um sistema universal de todas as coisas com uma forte dose de filosofia hermética, do tipo "o-que-está-acima-é-como-o-que-está-embaixo", que tudo unifica e cujo âmbito é universal. Mecânica, música, meteorologia, arquitetura, botânica, zoologia, arqueologia, fisiologia, agricultura: de fato, as sete artes liberais clássicas eram somente partes da empreitada pansófica.

Quando acrescentamos a esse tesouro as teorias médicas, físicas e teológicas originais de Paracelso, temos boa parte do itinerário do conhecimento associado aos textos originais dos fratres R.C. Aparentemente, eles estavam interessados em tudo. Mas era a intenção original dos Irmãos da Rosa-Cruz formarem ou encorajarem a formação de uma "ciência rosa-cruz"?

Se sim, então era de se esperar que os "rosa-cruzes" tivessem uma boa reputação no contexto da história da ciência: não possuíam. Visite o Museu da História da Ciência, em Oxford (mantido em um museu construído por ordem do entusiasta rosa-cruz Elias Ashmole, na década de 1670), e pergunte ao diretor se em sua opinião deveria haver uma sala dedicada aos rosa-cruzes. Imagino que não seria uma ideia recebida com boa vontade. Para o cientista moderno, o termo "Rosa-cruz" sugere "oculto”, "espiritual”, "nova era”, "astrologia”, "maçônico" e muitas outras coisas de que a moderna inquisição científica (ao menos na Grã-Bretanha) deseja, no momento, manter-se friamente separada (CHURTON, 2009, p. 50-51). 
A análise do autor citado é condizente com os estudos de Lomas (2007) sobre as origens da Ciência Moderna e suas possíveis descendências de grupos esotéricos. Para os autores, entre os fundadores da Royal Society, a famosa instituição para a promulgação do conhecimento científico no Ocidente, fundada na Londres do século XVII, estão nomes de peso de cientistas que muito se interessavam pelo estudo do simbolismo e das práticas esotéricas, entre eles Issac Newton (1643-1727) e o já mencionado Ashmole (1617-1692).

Não restam muitas dúvidas sobre o envolvimento de práticas e conhecimentos esotéricos entre os fundadores da Ciência Moderna. Tal prova pode ser identificada no amplo estudo que a Alquimia teve no início da modernidade. No entanto, os mesmos "herdeiros" dessas antigas práticas de cunho esotérico se esforçaram e lutaram para a desvinculação entre Ciência e religião, nascendo assim a Ciência empírico-positivista.

\section{O RENASCER DO SIMBÓLICO COMO LINGUAGEM "ENIGMÁTICA". O OCULTO E O ESOTÉRICO DE VOLTA AO CENÁRIO OCIDENTAL}

No último tópico desejamos constatar como os símbolos, sejam eles em formato de imagens ou de mitos, repercutiram durante a história da civilização ocidental, tendo sua principal difusão, no final da Idade Média, com o surgimento de fraternidades de cunho iniciático-esotérica, com seu expoente na fraternidade Rosa-Cruz.

Eliade (2011) e Campbell (2003) expõem que o sentido de um símbolo está sempre oculto, ou seja, o simbólico "revela-velando" os seus múltiplos significados. A partir do momento em que mencionamos um símbolo, sobretudo os incutidos em imagens, estamos necessariamente apontando para algo que está oculto. Portanto, falamos de ocultismo no sentido de interpretação de um símbolo, mas não como tendência a uma filosofia ou uma religião ocultista. Por exemplo, os símbolos aparecem nas religiões tradicionais, como no cristianismo, e ainda que permane- çam com seu véu oculto, não transformam o cristianismo em uma religião ocultista. Por sua vez, os símbolos também estão incutidos nas religiões e filosofias de mistérios, como a própria Rosa-Cruz e a Maçonaria, que, em certo sentido restrito, possuem traços próprios de ocultismo.

O interesse neste momento está em demonstrar que os símbolos sempre estiveram permeando a cultura ocidental, mesmo em momentos de grande perseguição religiosa em que se proibia o uso de símbolos sacros fora do âmbito eclesiástico. Embora houvesse, mesmo durante a Idade Média, círculos que se dedicavam ao estudo de outras tradições religiosas e do próprio esoterismo, os mesmos viviam o risco de serem apanhados pela Inquisição e veementemente condenados.

Em pesquisas anteriores, ${ }^{5}$ através da História, observamos a apropriação e, ao mesmo tempo, a iconoclastia dos símbolos existentes dentro das religiões. Um exemplo claro desse momento pode ser vislumbrado durante a transição da cultura ocidental pagã para a cultura ocidental cristã, que se desabrochava no início do cristianismo.

Essa transição se dera, sobretudo, no âmbito religioso com a conversão dos pagãos para o cristianismo nascente:

Os episódios mais importantes
dessa conversão são relatados por
Campbell (2008), que expõe duas
importantes etapas do "choque"
cultural com que o Cristianismo se
defrontou frente ao Paganismo. No
primeiro momento, ou seja, nos pri-
meiros séculos do nascimento e di-
fusão da nova religião, verificamos
uma violenta intolerância por parte
dos pagãos contra os cristãos, ten-
do em vista as perseguições dos Im-
peradores romanos e martírios dos
primeiros santos (...)

Pesquisas de bolsa de Iniciação Científica, com a apoio do CNPQ e da Fapesp, durante a graduação em Psicologia, em que investigamos, em linhas gerais, a relação entre Psicologia e símbolos religiosos. 
Entretanto, como avalia Marques (2005), após longos séculos de perseguições contra os cristãos, o Império Romano, que já estava próximo de sua queda, encontrava-se rendido à nova religião. Assim, sob o Imperador Constantino, O Grande, no século IV, o culto cristão passa a ser legítimo, tendo cessado todas as perseguições contra seus adeptos. Há uma grande mudança histórica, pois o Cristianismo passa a ser a religião predominante, tendo então lugar as perseguições contra os cultos pagãos, ou seja, de perseguidos, os cristãos passaram a ser perseguidores.

Existe uma vastidão de material para relatar este fato histórico, mas, para esta investigação, o fato mais importante é a maneira como a nova religião se estabeleceu. Hillgarth (2004) relata que o mundo sofreu uma difícil e sangrenta transição quando houve a mudança do politeísmo pagão para o monoteísmo cristão. A Igreja, que aos poucos ganhava terreno e a confiança de reis e imperadores, era totalmente intolerante a qualquer outro culto que não fosse cristão. Templos pagãos foram transformados em igrejas, símbolos, ícones e rituais foram destruídos. A crença e a prática da Astrologia, Numerologia, o misticismo antigo e todas as crenças e concepções das antigas religiões, de modo geral, foram tidas pelo Catolicismo como doutrinas "ocultas", portanto, “indubitavelmente", obras do demônio.

Podemos chamar este período de "dessacralização religiosa", pois, como aponta Campbell (2009), a cultura pagã fora substituída pelo advento do Cristianismo, sociedades iniciáticas foram proibidas e qualquer tentativa de culto às an- tigas divindades sofria sérias punições (RODRIGUES , 2014, p. 54-55).

A iconoclastia promovida pelo cristianismo nascente está bastante interligada com os movimentos esotéricos que tiveram seu surgimento no final da Idade Média. Com efeito, o ato de citar esse período histórico neste artigo consiste em explorar como os símbolos são importantes para as religiões e tradições filosóficas, sendo que mesmo durante períodos iconoclastas, como já citado, muitas tradições não se perderam, ao contrário, mantiveram-se vivas no imaginário coletivo, como bem propôs Jung (2008).

Um novo artigo poderia ser escrito caso nos detivéssemos nas teorias junguianas. Para tanto, não nos aprofundaremos nessa temática. Porém, historicamente, devemos mencionar que muito das tradições filosóficas, religiosas e culturais do mundo pagão passaram a ser transmitidas dentro de círculos herméticos durante toda a Idade Média, e em muitas bibliotecas de diversos mosteiros europeus. Nosso enfoque está na argumentação histórica de que essas tradições não foram totalmente destruídas durante os períodos iconoclastas. Muito da essência, cultura e ideias do mundo Antigo sobreviveram e, de certa forma, ressurgiram no final da Idade Média, começo da Idade Moderna, tendo como um dos seus expoentes a filosofia Rosa-Cruz.

Estudos recentes indicam que, muito provavelmente, os próprios construtores medievais das mais belas igrejas góticas europeias, conhecidos como maçons operativos, tenham entrado em contato com conhecimentos esotéricos. Essa suposição, como observado em estudo anterior (Rodrigues, 2014), reside na análise da simbologia de tais igrejas que, ao serem analisadas, fazem menção à Alquimia, Astrologia, Cabala, entre outras tradições ditas “ocultas”. É perigoso afirmar com exatidão que esses pedreiros faziam de seu "clube de construção" uma sociedade hermética, com estudos das antigas tradições. No entanto, esse dilema ainda permanece como um "enigma histórico" e suas contribuições 
para a perpetuação do esoterismo ocidental continuam abertas. Além disso, essas imagens "atípicas" presentes na ornamentação das mais famosas catedrais europeias podem levar a supor que, grupos ditos herméticos, permaneciam com os estudos e os antigos rituais que a "revolta iconoclasta" - promovida pelo cristianismo - tentou extinguir.

A tentativa iconoclasta de apagar antigos símbolos e rituais parece ter logrado certo sucesso por diversos séculos. No entanto, é com a perda do poder da hegemonia Católica - com o início das revoluções científicas e com a Reforma Protestante - que o chamado esoterismo ocidental pôde ganhar espaço, mesmo que sob críticas e perseguições. Esse esoterismo que a Rosa-Cruz, a Maçonaria, a Teosofia e a Gnose ajudaram a resgatar do "invólucro" oculto da Idade Média, passou a ser de domínio público, apesar do requisito ritualístico-iniciático em que o postulante é encaminhado a passar para que, assim, possa ter acesso aos conhecimentos arcanos. O domínio público, nesse caso, desabrocha no conhecimento geral de que antigas práticas, antigos símbolos não foram apagados, mas preservados durante períodos de perseguição.

Para Campbell (2003), o reavivamento simbólico indica que a linguagem passa a ter dois sentidos: o denotativo e o conotativo. $\mathrm{O}$ primeiro é o sentido original, aquele que se mostra, geralmente é visual. O conotativo, por sua vez, pretende decifrar o enigma do símbolo mediante uma linguagem filosófica e simbólica que "revela velando".

\section{CONSIDERAÇÕES FINAIS}

Um estudo da fraternidade Rosa-Cruz não é uma tarefa fácil. Essa dificuldade, talvez, esteja na investigação de qualquer sistema religioso. Embora a Rosa-Cruz não advogue para si o título de religião, ela é em si religiosa, visto que seus preceitos são de cunho religioso-metafísico, sendo sua história carregada de enigmas e incertezas que um historiador das religiões não pode afirmar com propriedade. Enigmas, incertezas e imprecisões são marcas bem características quando o estudio- so dos símbolos e das religiões se depara com as religiões ou as tradições ocultas.

O próprio termo ocultismo pode ser causa de profundos debates acadêmicos, mas, qual a diferença entre oculto e religião? Não seriam todas as religiões herdeiras de certo "ocultismo"? Afinal, não se é possível ver Deus, o que O torna, então, um Ser oculto. No entanto, essa terminologia não é utilizada e nem aceita pelas grandes religiões institucionalizadas. De modo geral, as superstições, as antigas tradições astrológicas, a Magia, a Cabala, a Gnose, entre outras tradições, receberam a designação de ocultas. Ora, tal menção, muitas vezes fora colocada em nível pejorativo, sobretudo durante a conversão do Ocidente para o cristianismo, em que antigos preceitos foram "demonizados" e tachados como ocultos, em contraponto à "claridade" e à "verdade" trazidas pela nova religião.

Com essa concepção, que perpassa ainda a mentalidade ocidental, é que muitas tradições religiosas e filosóficas, carregadas de ricos símbolos místicos, deixam de ser estudadas e investigadas por puro receio acadêmico. Receio esse configurado pela própria negatividade que o termo ocultismo emana. Embora existam dificuldades, para um estudo científico das religiões ou filosofias ditas ocultas, a academia não pode renegar toda uma tradição histórica existente por trás dessas tradições, como simples “objetos" não passíveis de análise crítica e histórica. Se as religiões tradicionais marginalizaram essas tradições, muitas vezes "demonizando-as", podemos considerar que o mundo acadêmico-científico faz o mesmo. Tal alusão é afirmada mediante nossa dificuldade em encontrar, no cenário brasileiro, artigos científicos, teses e dissertações que abordem essa temática.

A escolha da Rosa-Cruz, como base para este artigo, não ocorreu de maneira arbitrária; ao contrário, sua ampla difusão pelo mundo converteu-se na necessidade de compreendê-la. Por isso, um estudo científico é de extrema importância - ainda que o mesmo seja superficial e simples - por se tratar de uma Ordem cercada de enigmas e mistérios. 
Este artigo que propusemos escrever limitou-se na análise, em linhas gerais, dos parâmetros históricos nos quais surgiu a fraternidade Rosa-Cruz. A conclusão deste trabalho, de certa maneira, ocorreu no item 4, onde apontamos como os símbolos e an- tigas tradições esotéricas sobreviveram ao pesado tempo da História. O homem ainda vive sua dimensão simbólica, dimensão essa que o faz reviver antigos símbolos e ritos presentes em diversas sociedades esotéricas e iniciáticas.

\section{REFERÊNCIAS}

CAMPBELL, J. O Poder do Mito. São Paulo: Palas Athena, 2009.

. Tu és Isso: Transformando a Metáfora Religiosa. São Paulo: Madras, 2003.

CHURTON, T. A História da Rosa-Cruz: Os Invisíveis. São Paulo: Madras, 2009.

2008.

. O Mago da Franco-Maçonaria: A Vida e a Obra de Elias Ashmole. São Paulo: Madras,

ELIADE, M. O Sagrado e o Profano: A Essência das Religiões. São Paulo: Martins Fontes, 2011.

. História das Crenças e das Ideias Religiosas I: Da Idade da Pedra aos Mistérios de Elêusis. Rio de Janeiro: Zahar, 2010.

GRESCHAT, H. O que é Ciência da Religião? São Paulo: Paulinas, 2005.

JUNG, C. Os Arquétipos e o Inconsciente Coletivo. Petrópolis: Vozes, 2008

KINNEY, J. Esoterismo e Magia no Mundo Ocidental. São Paulo: Pensamento, 2006.

LOMAS, R. A Maçonaria e o Nascimento da Ciência Moderna. São Paulo: Madras, 2007.

LURKER, M. Dicionário de Simbologia. São Paulo: Martins Fontes, 2003.

MANTHÉIA, L. Ocultismo sem Mistério. São Paulo: Ibrasa, 1995.

MCINTOSH, C. A Rosa e a Cruz: História, Mitologia e Rituais das Ordens Esotéricas. Rio de Janeiro: Nova Era, 2001.

MILHOMENS, N. O Misticismo à Luz da Ciência. São Paulo: Ibrasa, 1997.

RODRIGUES, M. A Simbologia nos Monumentos Históricos de Portugal: Um Estudo da Possível Presença de Simbolismo Maçônico. Fragmentos de Cultura. V. 24, N.1. jan/mar de 2014. Disponível em: http://revistas.ucg.br/index.php/fragmentos/article/view/3198/1912 Acesso em: 22/07/2016

RODRIGUES. M. Maçonaria e Simbologia: Uma Análise do Preconceito Através da História e da Psicologia. Rio de Janeiro: Multifoco, 2014.

\section{DADOS DO AUTOR}

MARCEL HENRIQUE RODRIGUES

Doutorando em Ciência da Religião na Universidade Federal de Juiz de Fora. Mestre em Ciência da Religião pela Universidade Federal de Juiz de Fora. Graduado em Psicologia pelo Centro Universitário Salesiano. Juiz de Fora/MG - Brasil. marcel_symbols@hotmail.com

Submetido em: 5-7-2016

Aceito em: 3-3-2017 